\title{
RUPTURED UMBILICAL HERNIA IN HEPATIC CIRRHOSIS: A CASE REPORT
}

Mahesh Chandra Pandey1, Yojna Yadav²

${ }^{1}$ Assistant Professor, Department of Surgery, T.S.M. Medical College, Lucknow.

${ }^{2}$ Specialist Medical Officer, Department of Surgery, Composite Hospital, C.R.P.F., Bangalore.

\section{ABSTRACT}

We report a case of ruptured umbilical hernia in a patient with liver cirrhosis and ascites. The individual is working as a washerman in armed force and chronic alcoholic for last 15 years, admitted in emergency with spontaneous discharge of 6 litre of Ascetic fluid from a ruptured umbilical hernia with necrosis of overlying mass. He suffered extreme degree of ascites, which was totally unresponsive to medical treatment. Patient was managed in emergency with sterile dressing, fluid repletion and I/V Antibiotics. Primary closure of the defect done after excising the necrotic tissue under local anaesthesia. Currently, patient is on medical treatment and hernia repair is planned after medical optimisation.

\section{KEYWORDS}

Ascites, Alcoholic Liver Disease, Ruptured Umbilical Hernia.

HOW TO CITE THIS ARTICLE: Pandey MC, Yadav Y. Ruptured umbilical hernia in hepatic cirrhosis: a case report. J. Evolution Med. Dent. Sci. 2016;5(71):5229-5231, DOI: 10.14260/jemds/2016/1184

\section{INTRODUCTION}

Incidence of abdominal wall hernias in cirrhotic patients is as high as $20 \%$ and in cases of major ascites this number may increase up to $40 \% .^{1}$ It also carry an increased rate of per operative morbidity and mortality. Several factors such as increased abdominal tension due to presence of ascites, malnutrition and muscle wasting are major risk factor for development of abdominal wall hernia in cirrhotic patients. We report a case of ruptured umbilical hernia in a known case of alcoholic liver disease with cirrhosis and longstanding ascites.

\section{CASE STUDY}

Patient is 38-year-old male, a known case of alcoholic liver disease with portal hypertension and ascites. He is taking alcohol regularly for 15 years. He is working as a washerman in armed force and diagnosed with alcoholic liver disease with ascites and portal hypertension 3 years back and taking medical treatment without any relief in ascites. He developed umbilical hernia 6 months back without any episodes of obstruction and strangulation. The umbilical hernia ruptured, while straining during defecation and patient was rushed to emergency department in condition of shock.

$\mathrm{He}$ was admitted in emergency with spontaneous discharge of 6 litre of ascetic fluid from a ruptured umbilical hernia with necrosis of overlying mass. He suffered from extreme degree of ascites, which was totally unresponsive to medical treatment. On examination he was poorly nourished, anaemic not jaundiced; his pulse rate was $100 / \mathrm{min}$., B.P. was 90/60 mmHg. Patient was managed in emergency with sterile dressing, fluid repletion and I/V antibiotics. Primary closure of the defect done after excising the necrotic tissue under local anaesthesia. Currently, patient is on medical treatment and hernia repair is planned after medical optimisation.

Financial or Other, Competing Interest: None.

Submission 27-07-2016, Peer Review 19-08-2016,

Acceptance 26-08-2016, Published 03-09-2016.

Corresponding Author:

Dr. Mahesh Chandra Pandey,

Assistant Professor

Department of General Surgery,

T.S.M. Medical College, Lucknow.

E-mail: mp211177@gmail.com

DOI: $10.14260 /$ jemds/2016/1184

\section{DISCUSSION}

Umbilical hernias are common complication of persistent ascites. ${ }^{2}$ Strangulation (which can be precipitated by rapid removal of ascetic fluid) and rupture (which is preceded by cutaneous ulceration on surface of the hernia) are two lifethreatening complication of umbilical hernia. If these complications are present in umbilical hernia of cirrhotic patient, then there is increased mortality rate after repair. Small bowel evisceration is rare, but serious and potentially fatal complication of umbilical hernia in cirrhotic patients with ascites. $^{3}$

\section{Ruptured Umbilical Hernia with Necrosis of Overlying Mass}

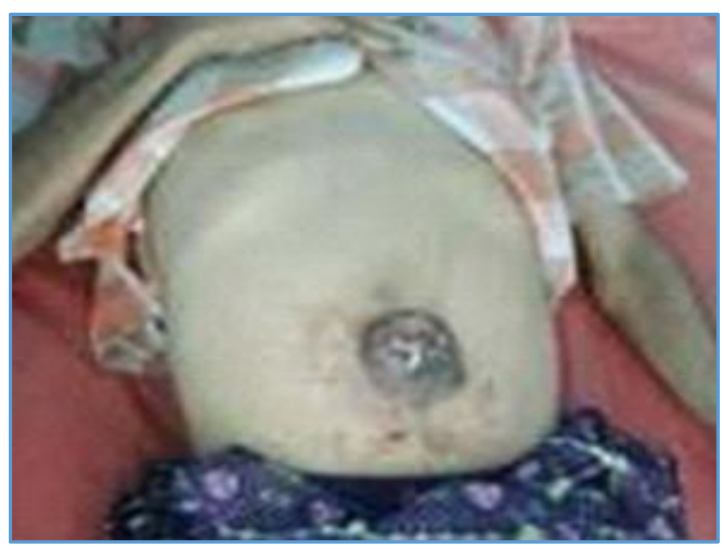

Fig. 1

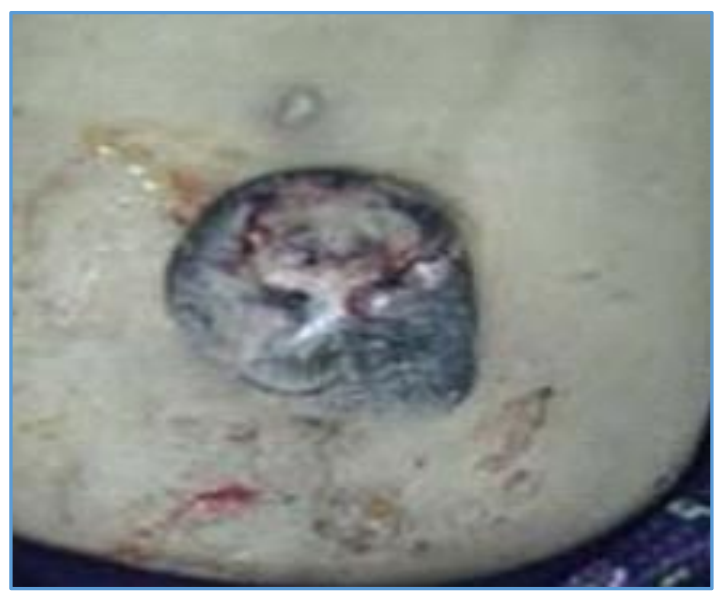

Fig. 2 


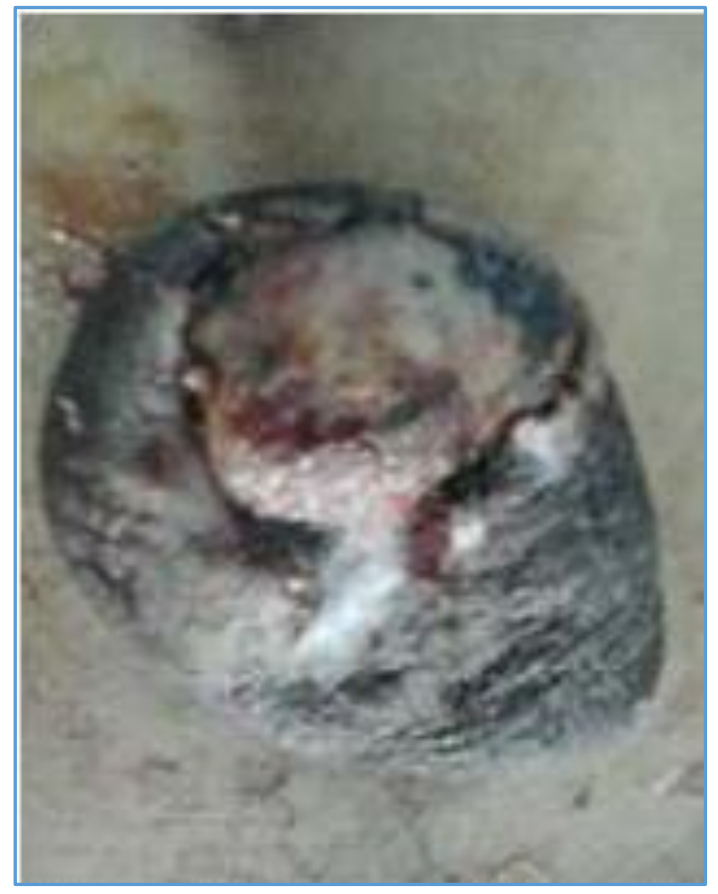

Fig. 3

Patients with both cirrhosis and ascites have 20\% risk of developing umbilical hernia and occurs exclusively when longstanding ascites is present. Treatment strategy for umbilical hernia in ascites patients depends on presence or absence of indication of liver transplant. 4 In transplant patients, herniorrhaphy must be performed at the time of transplantation and in the patients who are not the candidates for liver transplantation portocaval shunt or concomitant peritoneovenous shunt and herniorrhaphy should be considered.

\section{Ruptured Umbilical Hernia Repaired in L.A. with Excision of Necrosed Overlying Mass}

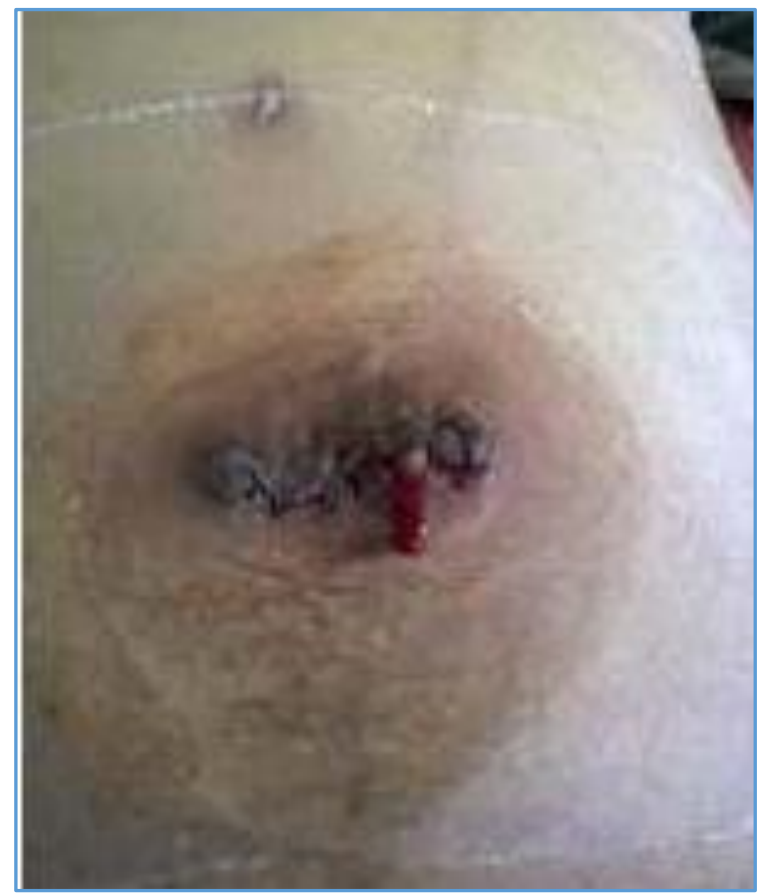

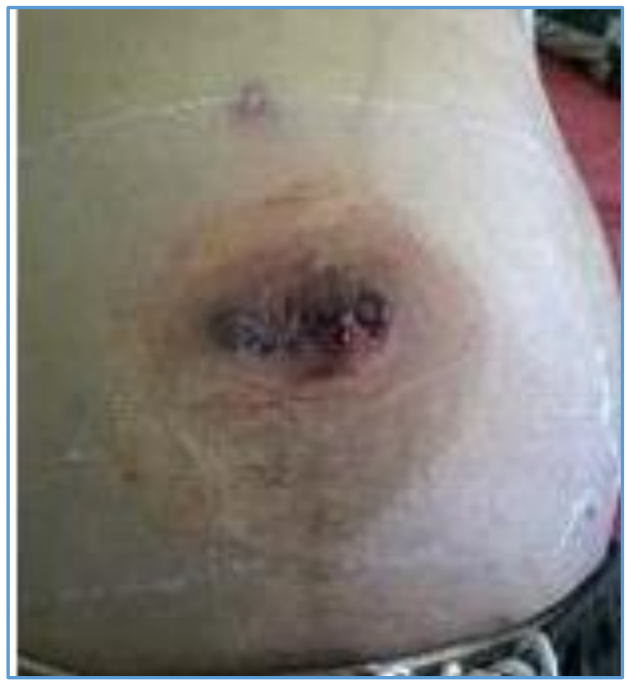

Fig. 5

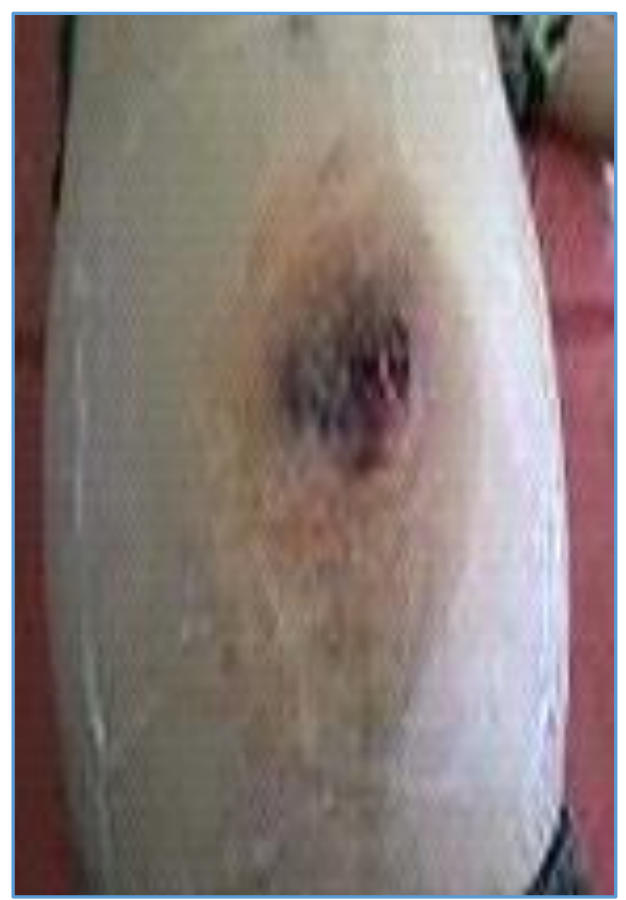

Fig. 6

Elective repair is the most effective choice, as it prevents complication with lower mortality. Portal decompression by Transjugular Intrahepatic Portosystemic Shunt (TIPS) with control of ascites may allow these patients to undergo surgery. 5

\section{CONCLUSION}

In ascites patients the most common complications of umbilical hernia are incarceration, ulceration and rupture. Optimising the patients with liver cirrhosis before elective umbilical hernia repair is crucial to minimise postoperative complication and reducing recurrence. 6 In rupture of the umbilical hernia, there is high mortality rate after surgical repair. Control of ascites is mandatory before elective repair of hernia. Portal decompression by Transjugular Intrahepatic Portosystemic Shunt (TIPS) with control of ascites allows patients of cirrhosis to undergo surgery and decreases the chances of severe recurrence of ascites.

Fig. 4 


\section{REFERENCES}

1. Andraus W, Pinheiro RS, Lai Q et al. Abdominal wall hernia in cirrhotic patient: emergency surgery results in higher morbidity and mortality. BMC Surgery 2015;15:65.

2. Ginsburg BY, Sharma AN. Spontaneous rupture of an umbilical hernia with evisceration. J Emerg Med 2006;30(2):155-7.

3. Choo EK, McElroy S. Spontaneous bowel evisceration in a patient with alcoholic cirrhosis and an umbilical hernia. J Emerg Med 2008;34(1):41-3.
4. Belghiti J, Durand F. Abdominal wall hernias in the setting of the cirrhosis. Semin Liver Dis 1997;17(3):219-26.

5. Triantos CK, Kehagias I, Nikolopoulou V, et al. Surgical repair of umbilical hernia in cirrosis with ascites. Am J Med Sci 2011;341(3):222-6.

6. Cho SW, Bhayani N, Newell P, et al. Umbilical hernia repair with signs of portal hypertension: surgical outcome and predictors of mortality. Arch Surg 2012;147(9):864-9. 